\title{
Differences in Branch Formation in Indeterminate and Determinate Tomato Types
}

\author{
Katsumi OHTA and Daisuke IKEDA \\ Faculty of Life and Environmental Science, Shimane University \\ Matsue, Shimane 690-8504, Japan
}

(Received June 29, 2015; Accepted September 3, 2015)

\begin{abstract}
Lateral shoot growth generated at leaf axils was investigated in indeterminate and determinate tomatoes (Solanum lycopersicum L.) during spring and autumn-winter cultivation. In indeterminate cultivars, the lateral shoots at the first and second nodes below the terminal flower bud grew longer than those at the third or lower nodes in spring and at 5 weeks after transplanting in autumn-winter. In determinate cultivars, lateral shoots at the first node below the terminal flower bud were shorter than those at lower nodes. Stem lengths and lateral shoot lengths of indeterminate cultivars were longer than those of determinate cultivars. In indeterminate cultivars, the lateral shoot of the second node below the terminal flower bud was suppressed significantly by flower bud removal but not by shoot removal (the terminal flower bud and the axillary bud from first node below the terminal flower bud) compared with untreated plants. In determinate cultivars, the lateral shoot of the second node below the terminal flower bud was not promoted by flower bud removal, but was significantly promoted by shoot removal compared with untreated plants. Terminal flower bud emergence was affected during lateral shoot elongation of indeterminate cultivars, but was not affected during lateral shoot elongation of determinate cultivars.
\end{abstract}

Keywords : axillary bud, lateral shoot, plant growth regulator, shoot removal, terminal flower bud

\section{INTRODUCTION}

Tomato plants differentiate a terminal flower bud on the apex of the main stem and formed flower truss, known as the determinate pattern with branching characteristics (Saito, 1982; Tabuchi, 2007). Then, the axillary bud adjacent to the terminal flower bud differentiates and grows as a uniaxial sympodial branch.

The lateral shoot that extend a single main branch and continues to grow is referred to as indeterminate (Fig. 1). These types are cultivated mainly for the fresh product market. In contrast, plants with a self-pruning growth habit with only short sympodial branches that form 1-4 flower trusses (Yeager, 1927) are described as determinate. A new apex can differentiate from the highest node below the terminal flower bud in this branching type. These cultivars are mainly grown for processing tomatoes (Abe et al., 1965).

In general, lateral shoots of indeterminate tomato cultivars need to be removed before becoming elongated to prevent nutrient competition between vegetative and reproductive organs. If lateral shoots are not removed, strong growth of shoots from some nodes occurs (Ohta, 2012). Because the sink strength of lateral shoots with flower trusses is stronger than that of the main stem (Shishido and Hori, 1991), strong growth of some lateral shoots may cause uneven distribution of photosynthetic products, resulting in undesirable effects on fruit production.

During tomato cultivation during winter and summer in the Netherlands, lateral shoots generated from the first or second nodes below the terminal flower bud are used to increase stem numbers per area in indeterminate cultivars and increase tomato yield (Heuvelink, 2005). Aoki (1981) devised the continuous pinching cultivation method, which uses the lateral shoots to improve fruit quality and increase yield. The utilization of lateral shoots can both promote high-quality fruits (Fukuchi et al., 2004; Saito et al., 2006; Kusakawa et al., 2013) and also increase crop yield (Sasaki et al., 2013). In contrast, for determinate tomato cultivars, lateral shoots are generally not removed to save labor and ensure yield (Arima and Nakamura, 1969; Fukui et al., 1990; Ito, 1992; Yanokuchi, 1997).

Differentiation of axillary buds occurs at every node during the growth of commercial cultivars. Although the axillary buds at lower nodes extend during the vegetative stage, the axillary buds at the upper nodes below the terminal bud do not extend much due to apical dominance (Saito, 1982; McSteen and Leyser, 2005). When the terminal flower bud at the shoot apex emerges and grows, the entire axillary bud in general begins to elongate. Branch formation in indeterminate cultivars differs from that in determinate ones. Also, the growth properties of lateral shoots generated from each node can be used as indices to increase yield and improve fruit quality. In addition, because the population of those who grow tomatoes in Japan is ageing, the ergonomics of this kind of work should be improved by developing a training method using lateral shoots originating from lower nodes. However, there has been little research to elucidate branching habits and the relationships between the emergence of the terminal flower bud and the elongation of lateral shoots in tomato. Because

Corresponding author : Katsumi Ohta, fax: $+81-852-32-6500$, e-mail : ohta@life.shimane-u.ac.jp 

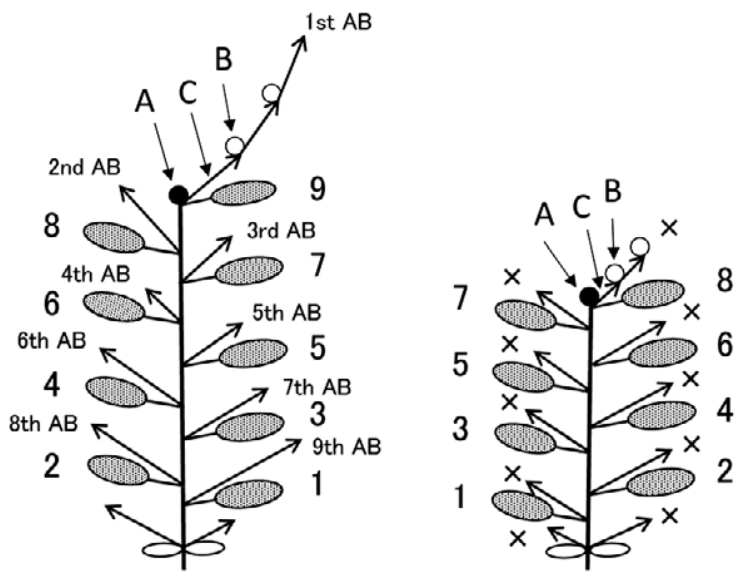

Fig. 1 Schematic diagrams of main stem, lateral shoot, leaves, and flower buds of indeterminate (Left) and determinate (Right) tomatoes. Dark shaded leaves (1-9) are true leaves, and leaves with white fill are cotyledons. $\mathrm{A}$ is the terminal flower bud on the main stem (first flower cluster), $\mathrm{B}$ is the terminal flower bud on the lateral shoot (second flower cluster), $\mathrm{C}$ is the lateral shoot of first node below the terminal flower bud, and axillary buds (ABs) are the lateral shoots at the second node below the terminal flower bud. $\times$ indicates determinate growth of lateral shoot.

tomatoes are cultivated year-round, differences in axillary bud emergence and lateral shoot growth were investigated under various temperatures and solar irradiance levels characteristic of spring or autumn-winter cultivation.

The purpose of our study was to clarify the differences in branching habits between indeterminate and determinate tomato cultivars during growth in spring or autumn-winter.

\section{MATERIALS AND METHODS}

\section{Plant materials and cultivation}

Six cultivars were used: 3 indeterminate cultivars, 'Mini Carol' (Sakata Seed Co., Ltd., Japan), 'Frutica' (Takii \& Co., Ltd., Japan), and 'House Momotaro' (Takii \& Co., Ltd., Japan); and 3 determinate cultivars, 'Suzukoma' (Tohoku Agricultural Research Center, National Agriculture and Food Research Organization and ZEN$\mathrm{NOH}$, Japan), 'Natsunokoma' (Morioka Station of the National Institute of Vegetables and Tea Science, Japan), and 'Shuho' (Nagano Chushin Agricultural Experiment Station, Japan).

Seeds were sown in Kanuma soil in plastic containers $(34.5 \mathrm{~cm} \times 27.0 \mathrm{~cm} \times 7.5 \mathrm{~cm})$ on April 8, 2013 for spring cultivation, and on October 7, 2013 for autumn-winter cultivation. All containers were placed in a greenhouse at Shimane University, Matsue City, Japan. Sixteen plants per cultivar were transplanted into black plastic pots (di- ameter $12 \mathrm{~cm}$ ) at a ratio of sandy loam: bark compost of 1 : $1(\mathrm{v} / \mathrm{v})$ with addition of fertilizer $\left(\mathrm{N}: \mathrm{P}_{2} \mathrm{O}_{5}: \mathrm{K}_{2} \mathrm{O}\right.$ at 1.9:1.1: $1.2 \mathrm{~kg} \mathrm{a}^{-1}$ ) on April 26 and October 25. When the sixth true leaf had fully expanded, 8 plants per cultivar were then transplanted into Wagner pots (1/2000 a) in the same potting substrate described above on May 22 and December 4. After transplanting into pots, soil moisture was maintained at $\mathrm{pF} 2.2$ using a tensiometer (DM-8, Takemura Electrical Factory Co., Ltd., Japan). All lateral shoots were left untrimmed and were trained using hemp string during the cultivation period. Pollination was performed by vibration three times per week.

Measurement of plant growth, and recording of air temperature and solar irradiance

Emergence of axillary buds was checked daily $(n=16$ plants per cultivar). For plants cultivated during spring, the lengths of the first lateral shoot generated from each node were measured once per week after transplanting (the integrated daily mean temperature for each week was 161 to $201^{\circ} \mathrm{C}$ ). During autumn-winter cultivation, measurements were performed once every two weeks (the integrated daily mean temperature for each two-week period was 193 to 2 $34^{\circ} \mathrm{C}$ ). Stem length from ground level to the terminal flower bud was measured at the final evaluation.

Air temperature at $1.5 \mathrm{~m}$ height above the ground level was measured every $60 \mathrm{~min}$ using a data logger (RX350TH, AS ONE Co., Ltd., Japan) from sowing through the final evaluation, and the average daily temperature was integrated (Table 1). During autumn-winter cultivation, a minimum temperature of $10^{\circ} \mathrm{C}$ was maintained after November 10 by heating the steel-frame greenhouse. Solar irradiance was measured using a pyrheliometer (\# 6450, Davis Instruments Co., USA), and the daily amount of solar irradiation was integrated.

Lateral shoot elongation after flower buds removal

Indeterminate 'Mini Carol' and determinate 'Suzukoma' were used for this experiment. Seeds were sown in plastic containers on April 14, 2013. The plants were potted on April 23, and transplanted into Wagner pots (1/5000 a) on May 10. Terminal flower buds (maximum bud length of about $1 \mathrm{~mm}$ ) were removed by pinching them off on May 15. Ten plants per treatment were evaluated. Lateral shoot lengths at the second node below the terminal flower bud were measured at $0,3,6$, and 9 days after treatment.

The lateral shoot elongation by shoot removal (including the terminal flower bud and the axillary bud at the first node below the flower bud)

Indeterminate 'Mini Carol' and determinate 'Suzukoma' were used for this experiment. Seeds were sown in plastic containers on July 26, 2013. All containers were placed in natural light with day/night (9:00-

Table 1 Cultivation periods, average temperatures, cumulative temperatures, and total integrated solar irradiance from sowing through final evaluation in spring and in autumn-winter cultivation groups.

\begin{tabular}{|c|c|c|c|c|c|c|}
\hline \multirow{2}{*}{$\begin{array}{l}\text { Cropping } \\
\text { season }\end{array}$} & \multirow{2}{*}{$\begin{array}{l}\text { Cultivation periods } \\
\text { (d) }\end{array}$} & \multicolumn{3}{|c|}{ Air temperature $\left({ }^{\circ} \mathrm{C}\right)$} & \multirow{2}{*}{$\begin{array}{c}\text { Cumulative } \\
\text { temperature }\left({ }^{\circ} \mathrm{C}\right)\end{array}$} & \multirow{2}{*}{$\begin{array}{l}\text { Total integrated sola } \\
\text { radiation }\left(\mathrm{MJ} \mathrm{m}^{-2}\right)\end{array}$} \\
\hline & & Maximum & Mean & Minimum & & \\
\hline Spring & 94 & 34.2 & 23.7 & 16.2 & 2255 & 1639 \\
\hline Autumn-winter & 135 & 24.1 & 16.4 & 12.9 & 2206 & 783 \\
\hline
\end{tabular}




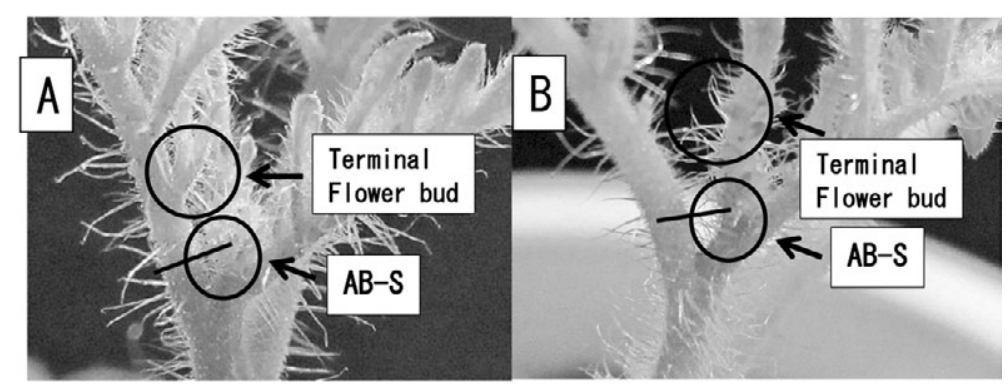

Fig. 2 Axillary bud of the second node (AB-S) below the terminal flower bud in the indeterminate tomato cultivar 'Mini Carol' (A) and the determinate cultivar 'Suzukoma' (B). Axillary buds of the first node below the terminal flower bud are located behind the terminal flower bud. Solid lines indicate the position of shoot removal on the stem.

18:00/18:00-9:00) temperatures controlled to $28 / 20^{\circ} \mathrm{C}$, respectively. The plants were potted on August 5, and transplanted into Wagner pots (1/5000 a) on August 23. The upper portions of stems were removed at the second node below the terminal flower bud on August 30 (Fig. 2). Ten plants per treatment were evaluated. Lateral shoot lengths at the second node below the terminal flower bud were measured at $0,3,6$, and $9 \mathrm{~d}$ after treatment.

\section{RESULTS}

The emergence of the axillary bud in 6 cultivars was observed from May 12 to May 15 in plants grown during spring, and from November 13 to November 15 in plants grown during autumn-winter. Figure 3 shows that axillary buds were generated from the first true leaf node in 5 of 6 cultivars (excluding 'Frutica', in which axillary buds were generated from the cotyledonary node). During spring cultivation, axillary bud emergence at the third and fourth nodes below the terminal flower bud in indeterminate cultivars and the third node below the terminal flower bud in determinate ones occurred at almost the same time, or 0 to 2 days later than at upper nodes. In contrast, during autumn-winter cultivation, the axillary buds at true leaf nodes were generated sequentially from the lower to upper nodes in all cultivars.

Figure 4 shows that the lateral shoots at the first and second nodes below the terminal flower bud in the indeterminate cultivars during spring elongated more than those at lower nodes at 3 weeks after transplanting, and eventually reached 38 to $43 \mathrm{~cm}$ at 5 weeks. The lateral shoot lengths at the third to fifth nodes below the terminal flower bud at 3 weeks were shorter than those at the upper and lower nodes, and these shoots continued growing until 7 weeks. In contrast, the lateral shoot lengths at the first node below the terminal flower bud of the determinate cultivars were short, from 5 to $8 \mathrm{~cm}$ at 5 weeks after transplanting. Lateral shoots at the second to eighth nodes below the terminal flower bud continued to grow, reaching nearly identical lengths at 7 weeks after transplanting. The lateral shoots produced from the cotyledon nodes were shorter than those at the lower true leaf nodes at 7 weeks.

For the indeterminate cultivars in autumn-winter, lateral shoot lengths at nodes at and below the third node below the terminal flower bud were shorter than those at the first and second nodes below the terminal flower bud at
5 weeks after transplanting. The subsequent growth of shoots at these lower nodes was strong 7 weeks after transplanting (Fig. 5). However, in the determinate cultivars, the lengths of the lateral shoots at each node were nearly the same at 5 and 11 weeks after transplanting, except for those at the first node below the terminal flower bud. The lateral shoots arising from the cotyledon nodes were short compared to those that grew from true leaf nodes at 11 weeks after transplanting, due to delayed axillary bud emergence.

Table 2 shows that stem lengths were significantly shorter in spring than in autumn-winter, and were longer in indeterminate than in determinate cultivars. Lateral shoot lengths were significantly longer during spring cultivation than during autumn-winter cultivation, and were also longer in indeterminate cultivars than in determinate ones. Mean internode lengths were similar to results for stem lengths. Stem, lateral shoot, and mean internode lengths were significantly different among these 6 cultivars.

Figure 6 shows that in the indeterminate cultivar 'Mini Carol', lateral shoot length at the second node below the terminal flower bud was significantly suppressed by flower bud removal at 6 and 9 days after treatment, compared to that in untreated plants. Lateral shoot lengths at the second node below the terminal flower bud did not differ after shoot removal compared with untreated plants. Figure 7 shows that the lateral shoot length at the second node below the terminal flower bud in the determinate cultivar 'Suzukoma' was not significantly different between plants with flower buds removed and untreated plants. The lateral shoot length at the second node below the terminal flower bud increased significantly at 6 and 9 days after shoot removal compared with that of untreated plants.

Figure 8 summarizes the results of Figs. 6 and 7 . Lateral shoot $\left(\mathrm{C}_{1}\right)$ growth at the second node below the terminal flower bud was analyzed in indeterminate cultivars in the presence of either the terminal flower bud $\left(\mathrm{A}_{1}\right)$ or the axillary bud $\left(B_{1}\right)$. The growth of $C_{1}$ was suppressed in the presence of only $B_{1}$, and growth of $C_{1}$ did not change if both $A_{1}$ and $B_{1}$ were removed. Thus, the presence of $A_{1}$ promoted growth of $C_{1}$ in indeterminate cultivars (Fig. 8). In contrast, when lateral shoot $\left(\mathrm{C}_{2}\right)$ growth was analyzed in determinate cultivars in the presence of either the terminal flower bud $\left(\mathrm{A}_{2}\right)$ or the axillary bud $\left(\mathrm{B}_{2}\right)$, the growth of $\mathrm{C}_{2}$ in the presence of only $\mathrm{B}_{2}$ did not change (growth was suppressed). However, the growth of $\mathrm{C}_{2}$ was accelerated if 

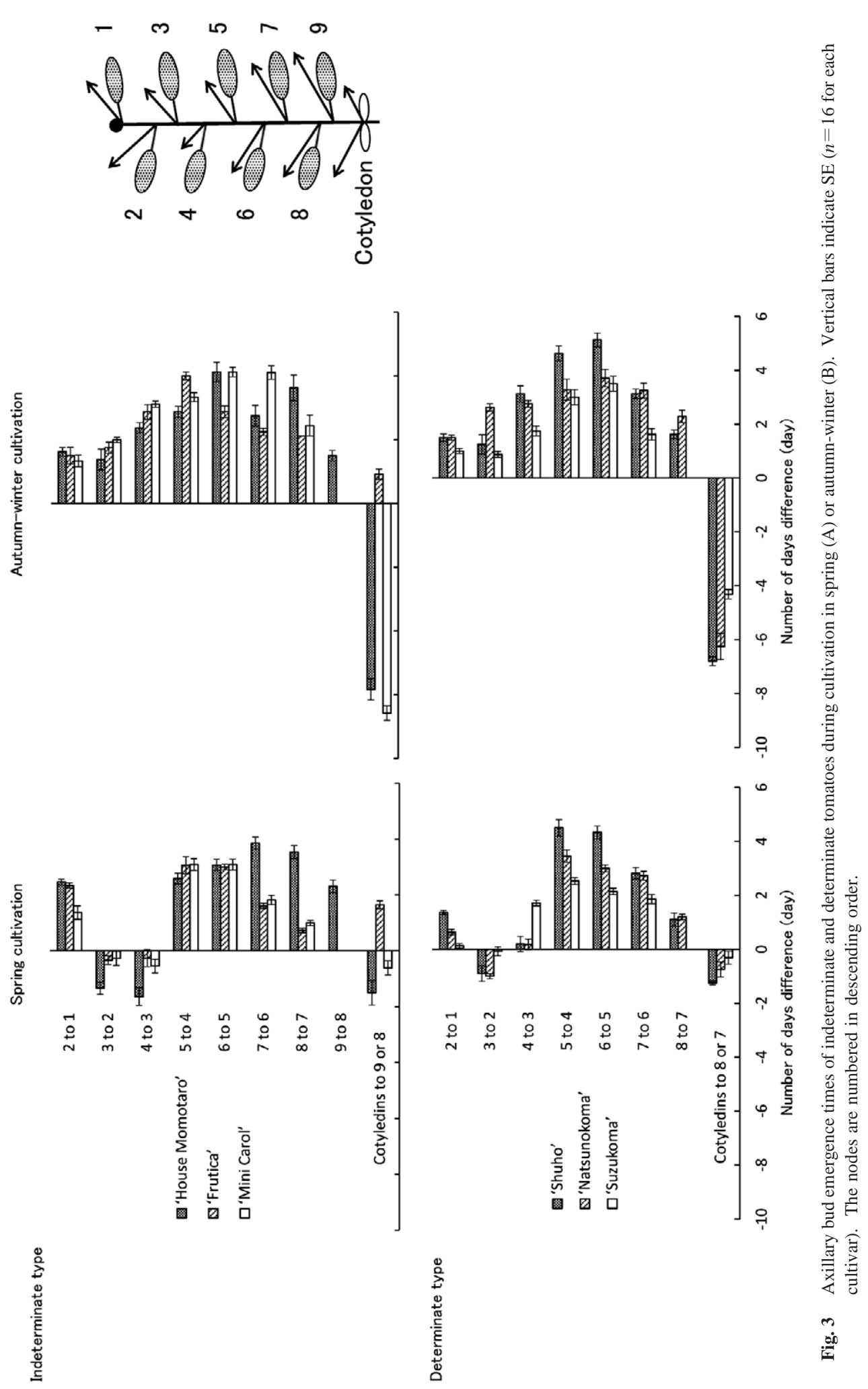

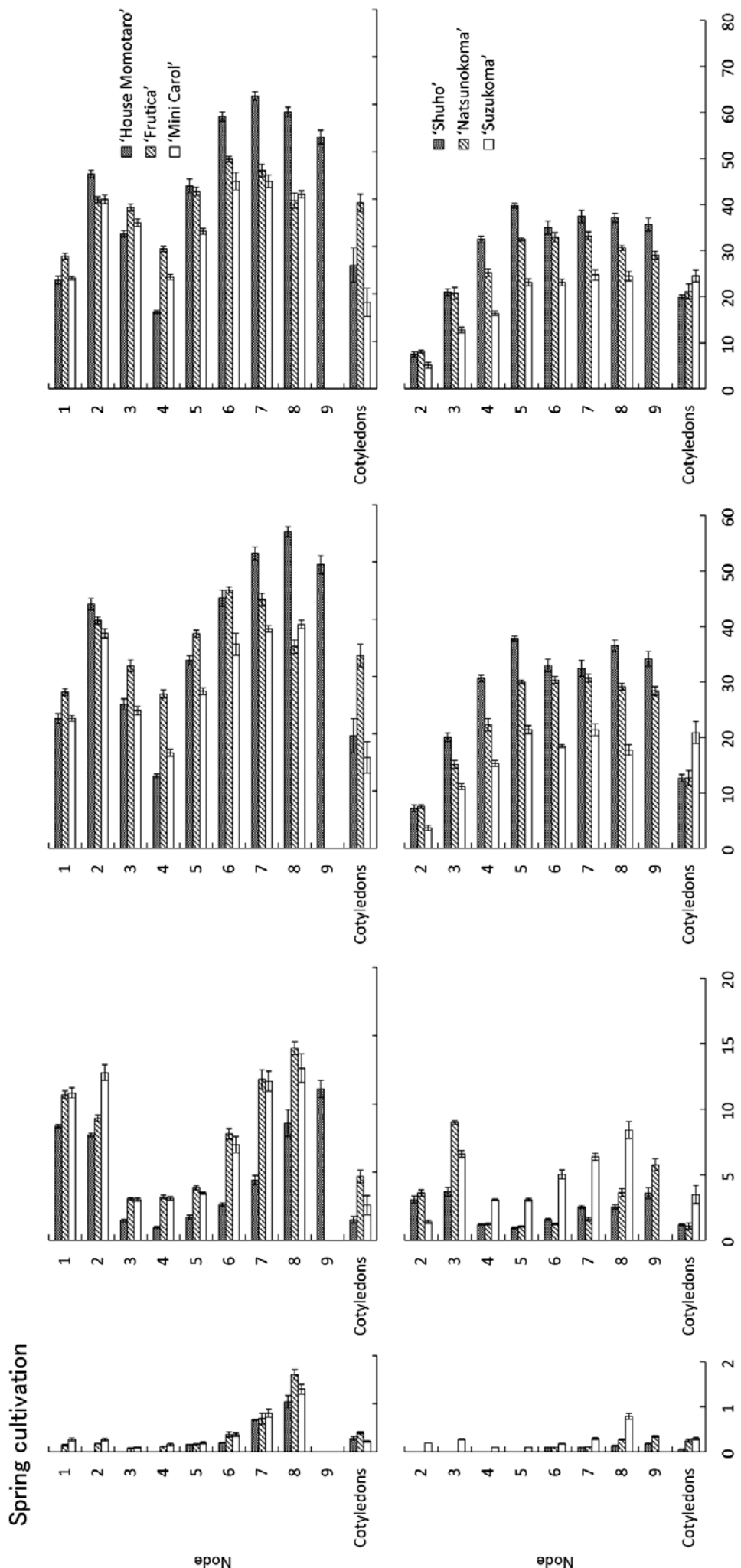

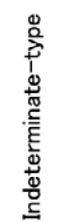

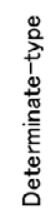

әpoN

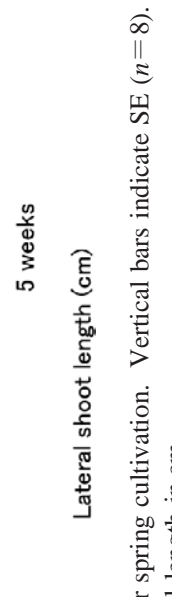

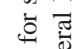

政 

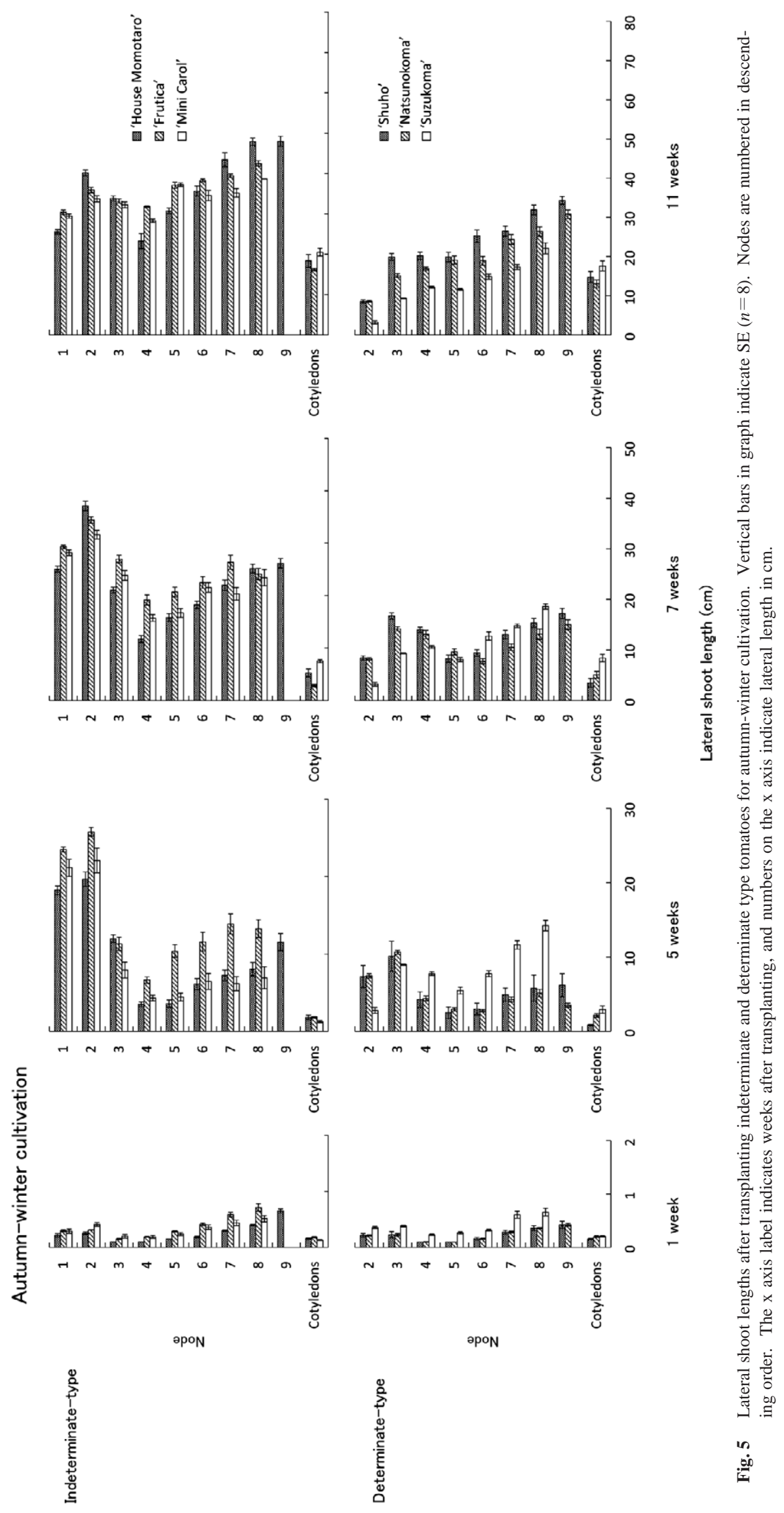


\section{BRANCH FORMATION IN TOMATOES}

Table 2 Stem lengths, lateral shoot lengths, and mean internode lengths at 7 and 11 weeks after transplanting of 6 tomato cultivars grown in spring and autumn-winter.

\begin{tabular}{|c|c|c|c|c|c|c|}
\hline Cropping season & Branching type & Cultivar & $\begin{array}{l}\text { Stem } \\
\text { length } \\
(\mathrm{cm})\end{array}$ & $\begin{array}{l}\text { Lateral shoot } \\
\text { length } \\
(\mathrm{cm})\end{array}$ & $\begin{array}{r}\mathrm{M} \\
\text { internod } \\
\text { (c }\end{array}$ & $\begin{array}{l}\text { an } \\
\text { n) }\end{array}$ \\
\hline \multirow{6}{*}{ Spring } & \multirow{3}{*}{ Indeterminate } & 'Mini Carol' & $34.6 \mathrm{~d}$ & $32.6 c^{y}(1-8)$ & $3.8 \mathrm{~d}$ & $(1-8)$ \\
\hline & & 'Frutica' & $28.9 \mathrm{c}$ & $39.0 \mathrm{~d} \quad(1-8)$ & $3.2 \mathrm{c}$ & $(1-8)$ \\
\hline & & 'House Momotaro' & $33.7 \mathrm{~d}$ & $41.8 \mathrm{~d} \quad(1-9)$ & $3.4 \mathrm{c}$ & $(1-9)$ \\
\hline & \multirow{3}{*}{ Determinate } & 'Suzukoma' & $22.0 \mathrm{a}$ & $19.8 \mathrm{a} \quad(1-7)$ & $2.7 \mathrm{~b}$ & $(1-7)$ \\
\hline & & 'Natsunokoma' & $21.8 \mathrm{a}$ & $26.1 \mathrm{~b} \quad(1-8)$ & $2.4 \mathrm{a}$ & $(1-8)$ \\
\hline & & 'Shuho' & $25.6 \mathrm{~b}$ & $28.6 \mathrm{bc}(1-8)$ & $2.8 \mathrm{~b}$ & $(1-8)$ \\
\hline \multirow{6}{*}{ Autumn-winter } & \multirow{3}{*}{ Indeterminate } & 'Mini Carol' & $39.8 \mathrm{~d}$ & $30.8 \mathrm{c} \quad(1-8)$ & $4.4 \mathrm{~d}$ & $(1-8)$ \\
\hline & & 'Frutica' & $35.7 \mathrm{bc}$ & $34.0 \mathrm{~cd}(1-8)$ & $4.0 \mathrm{c}$ & $(1-8)$ \\
\hline & & 'House Momotaro' & $39.3 \mathrm{~cd}$ & $34.4 \mathrm{~d} \quad(1-9)$ & $3.9 \mathrm{c}$ & $(1-9)$ \\
\hline & \multirow{3}{*}{ Determinate } & 'Suzukoma' & $26.8 \mathrm{a}$ & $14.3 \mathrm{a} \quad(1-7)$ & $3.4 \mathrm{~b}$ & $(1-7)$ \\
\hline & & 'Natsunokoma' & $26.0 \mathrm{a}$ & $19.2 \mathrm{~b} \quad(1-8)$ & $2.9 \mathrm{a}$ & $(1-8)$ \\
\hline & & 'Shuho' & $31.9 \mathrm{~b}$ & $22.3 \mathrm{~b} \quad(1-8)$ & $3.5 \mathrm{bc}$ & $(1-8)$ \\
\hline & Cropping season $(\mathrm{Cr})$ & & $* *^{x}$ & $* *$ & $* *$ & \\
\hline & Branching type (B) & & $* *$ & $* *$ & $* *$ & \\
\hline & Cultivar $(\mathrm{Cu})$ & & $* *$ & $* *$ & $* *$ & \\
\hline & $\mathrm{Cr} \times \mathrm{B}$ & & NS & $*$ & $* *$ & \\
\hline & $\mathrm{Cr} \times \mathrm{Cu}$ & & NS & $*$ & $* *$ & \\
\hline & $\mathrm{B} \times \mathrm{Cu}$ & & NS & NS & NS & \\
\hline & $\mathrm{Cr} \times \mathrm{B} \times \mathrm{Cu}$ & & NS & NS & NS & \\
\hline
\end{tabular}

${ }^{\mathrm{z}}$ Stem length is the vertical distance from ground level to the terminal flower bud.

${ }^{y}$ Different letters following stem lengths within the same season (6 cultivars each) indicate significant differences by

Tukey's multiple range test $(P<0.05, n=8)$ for each cultivar.

* and $* *$ indicate significant differences $(P<0.05$ and $P<0.01)$; NS: not significant (multi-way ANOVA).
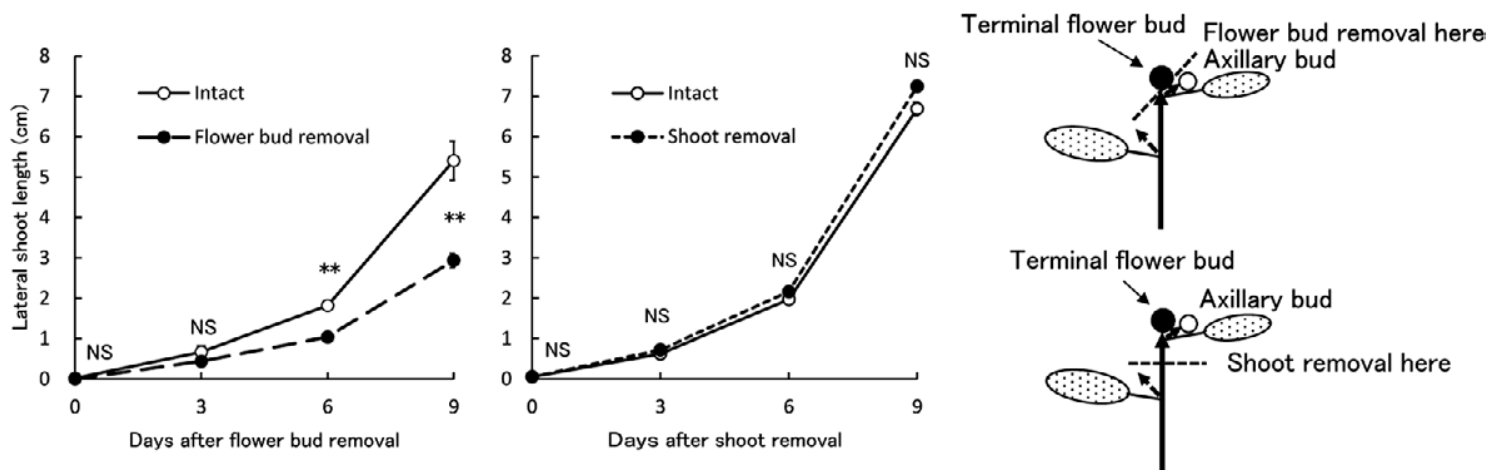

Fig. 6 Lateral shoot length at the second node below the terminal flower bud after flower bud removal and shoot removal above the second node below the terminal flower bud in indeterminate tomato cultivar 'Mini Carol'. Flower bud removal and shoot removal positions are indicated here by the dotted line, which corresponds to the solid line in Fig. 2 (A). Significant difference was shown as **: $P<0.05$, NS: not significant $(t$-test). Vertical bars in graph indicate SE $(n=10)$.
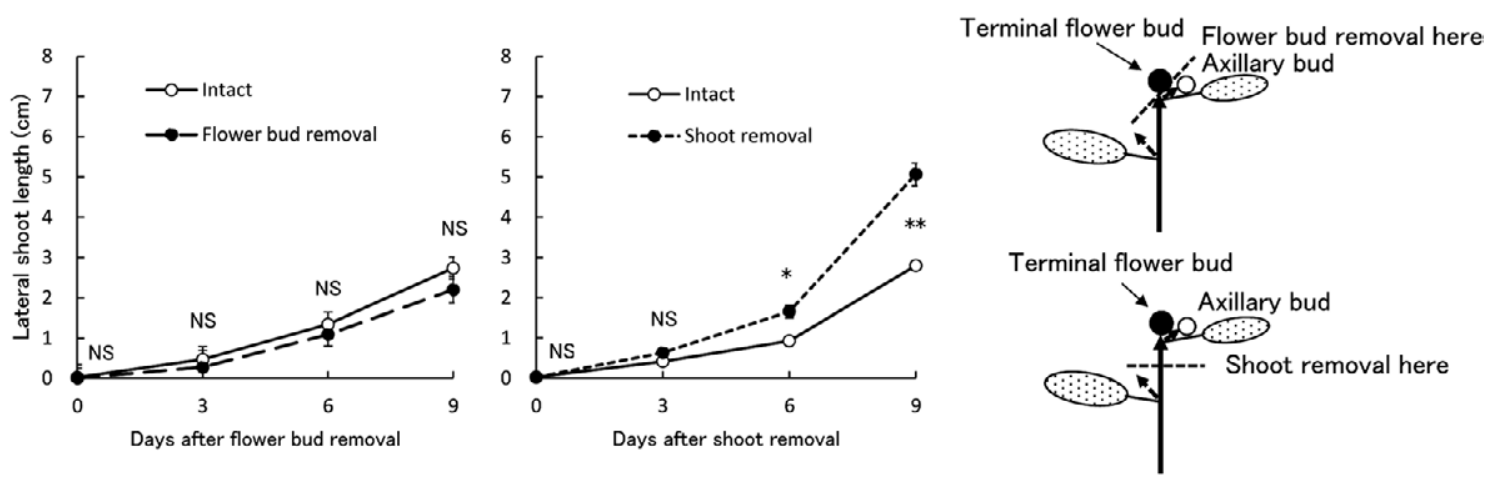

Fig. 7 Lateral shoot length at the second node below the terminal flower bud after flower bud removal and shoot removal above the second node below the terminal flower bud of determinate tomato cultivar 'Suzukoma'. Flower bud removal and shoot removal positions are indicated here by the dotted line, which corresponds to the solid line in Fig. 2 (B). Significant differences are indicated as $* *$ : $P<0.01, *: P<0.05$, NS: not significant $(t$-test). Vertical bars in graph indicate SE $(n=10)$. 


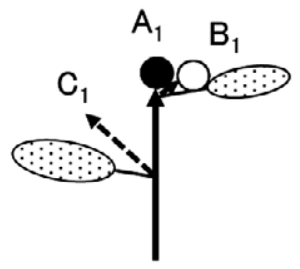

Indeterminate type

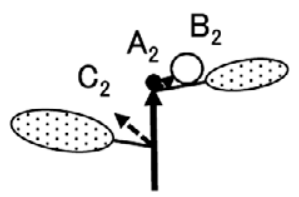

A : Terminal flower bud

B : Axillary bud

C : Lateral shoot

\begin{tabular}{|c|c|c|c|c|c|}
\hline & \multirow[b]{2}{*}{ Apical bud } & \multirow{2}{*}{\multicolumn{2}{|c|}{$\mathrm{C}_{1}$ growth }} & \multicolumn{2}{|c|}{ Effect on the lateral shoot growth } \\
\hline & & & & Terminal flower bud $\left(A_{1}\right)$ & Axillary bud $\left(B_{1}\right)$ \\
\hline \multirow{4}{*}{ Indeterminate type } & $A_{1}$ and $B_{1}$ & $\rightarrow$ & Normal & \multirow{3}{*}{ Promoted } & \multirow{3}{*}{ Suppressed } \\
\hline & $\mathrm{B}_{1}$ only & $\rightarrow$ & Suppressed & & \\
\hline & None & $\rightarrow$ & Normal & & \\
\hline & Apical bud & & $\mathrm{C}_{2}$ growth & \begin{tabular}{|l|} 
Terminal flower bud $\left(A_{2}\right)$ \\
\end{tabular} & Axillary bud $\left(B_{2}\right)$ \\
\hline \multirow{3}{*}{ Determinate type } & $A_{2}$ and $B_{2}$ & $\rightarrow$ & Normal & \multirow{3}{*}{ Not promoted } & \multirow{3}{*}{ Suppressed } \\
\hline & $\mathrm{B}_{2}$ only & $\rightarrow$ & Normal & & \\
\hline & None & $\rightarrow$ & Promoted & & \\
\hline
\end{tabular}

Fig. 8 Relationships among terminal flower buds $\left(A_{1}, A_{2}\right)$, axillary buds $\left(B_{1}, B_{2}\right)$, and lateral shoot growth $\left(C_{1}, C_{2}\right)$ of indeterminate and determinate tomatoes.

both $\mathrm{A}_{2}$ and $\mathrm{B}_{2}$ were removed. Thus, the presence $\mathrm{A}_{2}$ did not promote the growth of $\mathrm{C}_{2}$ in determinate cultivars.

\section{DISCUSSION}

Although the cumulative temperatures during the investigation period were almost the same (about $2200^{\circ} \mathrm{C}$ ) during both spring and autumn-winter cultivation (Table 1), stem, lateral shoot, and mean internode lengths differed among seasons, branching types, and cultivars (Table 2). Lower mean air temperatures $\left(7^{\circ} \mathrm{C}\right)$ and less than half the integrated solar irradiance reduces vegetative growth and results in shorter lateral shoots during autumn-winter relative to spring (Table 1). However, the branching habits of the two cultivar types were not significantly different during these two cultivation seasons (Figs. 4 and 5).

The expansion of the axillary bud was delayed in both branching types in spring at the third or fourth nodes below the terminal flower bud compared with the second node below the terminal flower bud, but not in autumn-winter (Fig. 3). Tucker (1975) reported that lateral bud emergence was delayed and its length was suppressed by increasing internode length under far-red light treatment in tomato plants. We surmise that the delay of axillary bud emergence from the third and/or fourth nodes below the terminal flower bud was due to internode extension under higher temperatures in spring.

In spring, lateral shoot lengths at the fourth and first nodes below the first terminal flower bud were suppressed at 7 weeks after transplanting, compared to those at lower nodes in both indeterminate and determinate types (Fig. 4). Also, in autumn-winter, lateral shoot growth showed a similar tendency as in spring at 11 weeks after transplanting in both types (Fig. 5). Our results indicated that branch formation in the indeterminate cultivars was very different from that in the determinate ones.

Flower bud removal or shoot removal were thus carried out to clarify the roles of the terminal flower bud and axillary bud at the first node below the terminal flower bud, and to clarify the reason that lateral shoots at the second node below the terminal flower bud elongate more than those at other nodes below the third node at 3 or 5 weeks after transplanting in spring or autumn-winter, respectively. In indeterminate cultivars, the lateral shoot lengths at the second node below the terminal flower bud were suppressed significantly at 6 and 9 days after flower bud removal, but these shoots did not elongate upon shoot removal (Fig. 6). In determinate types, growth of the lateral shoots at the second node below the terminal flower bud was not suppressed by flower bud removal compared with untreated plants, but lengths of these shoots increased significantly at 6 and 9 days after shoot removal (Fig. 7). Hence, these results suggest that the terminal flower bud promoted the growth of lateral shoots at the second node below the terminal flower bud in indeterminate cultivars, but not in determinate cultivars (Fig. 8). In contrast, the presence of the axillary bud at the first node below the terminal flower bud seemed to suppress elongation of the axillary bud at the second node in both types of cultivars. Because emergence of the terminal flower bud occurred earlier than emergence of the axillary bud at the second node, the effect of the terminal flower bud on lateral shoot growth might be stronger than that on the axillary bud in both types of cultivars.

Auxin is produced in the apical bud and young expanding leaves in Arabidopsis, Brussels sprouts, pea, and tomato (Tucker, 1976; Thomas, 1983; Zhu and Davis, 1997; Ljung et al., 2001). In the indeterminate cultivars, if the auxin concentration that suppresses lateral shoot elongation decreases temporarily upon ablation of the apical meristem or emergence of the terminal flower bud, the lateral shoot at the second node below the terminal flower bud elongates due to high cytokinin concentrations in the main stem. According to Shimizu-Sato et al. (2009), reduced 
auxin concentration in the apical organs is a factor involved in increased cytokinin concentrations. However, in determinate cultivars, emergence of the terminal flower bud did not promote the growth of lateral shoots. The much shorter stem lengths in determinate cultivars compared indeterminate cultivars suggests that auxin concentrations in the apical organs including the terminal flower bud might differ much from those of non-flowering terminal buds. Furthermore, auxin concentrations in apical organs including the terminal flower bud might be related to branching habit in tomato plants. Dun et al. (2012), Koltai et al. (2010), Leyser (2009), Ongaro and Leyser (2008), and Tucker (1976) reported that the actions of auxin, cytokinin, and strigolactone interact during the growth of axillary buds in Arabidopsis, pea, and tomato. Further study regarding fluctuations in plant growth regulator concentrations including auxin is needed to clarify the differences between these two branching types in tomato.

This experiment described and analyzed the branching habit differences between indeterminate and determinate tomato cultivars. While the emergence of the terminal flower bud affected the elongation of lateral shoots in indeterminate cultivars, it did not affect the elongation of lateral shoots in determinate cultivars. Therefore, special management of the lateral shoots is needed to improve fruit production. For example, the appropriate management method for high fruit yield and fruit quality depends on branching type, whether determinate or indeterminate. For indeterminate cultivars to set fruit in the proper position, it is necessary to consider the position and timing of lateral shoot pinching and the timing of lateral shoot removal. For determinate cultivars, limiting the number of lateral shoots or training the vines vertically helps to avoid diseases under high temperature and humidity conditions.

\section{ACKNOWLEDGEMENTS}

We are grateful to Prof. H. Itamura for his thoughtful comments and support over the course of this study.

We appreciate the Tohoku Agricultural Research Center, National Agricultural Research Center, and ZEN-NOH for providing the 'Suzukoma' cultivar for our experiment.

\section{REFERENCES}

Abe, I., Kamimura, S., Seyama, N. 1965. Studies on the unstaked culture for processing tomatoes. Some experiments on the direct seeding. (in Japanese with English summary) Bull. Natl. Inst. Hortic. C. 3: 73-87.

Aoki, H. 1981. New training method of tomatoes. Continuous pinching cultivation. (in Japanese) Agric. Hortic. 56: 10431046.

Arima, H., Nakamura, H. 1969. Studies on the laborsaving culture of processing tomato. (in Japanese with English summary) J. Fac. Agric. Shinshu Univ. 6: 83-99.

Dun, E. A., Germain, A. de S., Rameau, C., Beveridge, C. A. 2012. Antagonistic action of strigolactone and cytokinin in bud outgrowth control. Plant Physiol. 158: 487-498.

Fukuchi, N., Motoori, S., Udagawa, Y. 2004. Effects of fruit thinning and training on tomato yield and fruit soluble solids content. (in Japanese with English summary) Hortic. Res. 3:
277-281.

Fukui, H., Iguchi, H., Nakamura, M. 1990. Characteristics of determinate type tomatoes. (in Japanese with English summary) Res. Bull. Fac. Agric. Gifu Univ. 55: 125-135.

Heuvelink, E. 2005. Chap. 3. Developmental process. Tomatoes. (ed. by Heuvelink, E.), CAB Int. London, p 53-84.

Ito, M. 1992. A study on the establishment of breeding technology for labor-saving harvest facing breeding in the processing tomatoes. (in Japanese) PhD thesis. Tohoku Univ., Sendai, pp 275.

Koltai, H., Lekala, A. P., Bhattacharya, C., Mayzlish-Gati, E., Resnick, N., Wininger, S., Dor, E., Yoneyama, K., Yoneyama, K., Hershenhorn, J., Joel, D. M., Kapulnik, Y. 2010. A tomato strigolactone-impaired mutant displays aberrant shoot morphology and plant interactions. J. Exp. Bot. 61: 17391749.

Kusakawa, T., Fukuchi, N., Inoue, M. 2013. Relationship between leaf weight on lateral shoots below the tomato truss and fruit soluble solids content. (in Japanese with English summary) CAFRC Res. Bul. 5: 93-99.

Leyser, O. 2009. The control of shoot branching: an example of plant information processing. Plant Cell and Environ. 32: 694-703.

Ljung, K., Bhalerao, P. R., Sandberg, G. 2001. Sites and homeostatic control of auxin biosynthesis in Arabidopsis during vegetative growth. Plant J. 28: 465-474.

McSteen, P., Leyser, O. 2005. Shoot branching. Annu. Rev. Plant Biol. 56: 353-374.

Ohta, K. 2012. Pattern of lateral shoot elongation and the lateral shoot elongation of two nodes immediately below flower truss in tomato plants. (in Japanese) Hortic. Res. (Japan) 11 (Suppl. 1): 382 .

Ongaro, V., Leyser, O. 2008. Hormonal control of shoot branching. J. Exp. Bot. 59: 67-74.

Saito, T. 1982. Chap. 1. Flower bud differentiation and development of fruits and vegetables. Section 1 flowering habit, Section 2 differentiation process of flower bud. (in Japanese) Vegetable crop science. Fruit vegetables. Rural Cult. Assoc. Tokyo, p 64-87.

Saito, T., Fukuda, N., Nishimura, S. 2006. Effects of salinity, planting density and lateral shoot leaves under truss on yield and total soluble solids of tomato fruits grown in hydroponics. (in Japanese with English summary) Hortic. Res. 5: 415-419.

Sasaki, H., Kawasaki, Y., Yasuba, K., Suzuki, K., Takaichi, M. 2013. Effect of retaining basal lateral shoot on total soluble solids and yield in tomato trained on a high wire system. (in Japanese with English summary) Bull. Natl. Inst. Veg. and Tea Sci. 12: 1-6.

Shimizu-Sato, S., Tanaka, M., Mori, H. 2009. Auxin-cytokinin interactions in the control of shoot branching. Plant Mol. Biol. 69: 429-435.

Shishido, Y., Hori, Y. 1991. The role of leaf as affected by phyllotaxis and leaf histology on the development of the fruit in tomato. (in Japanese with English summary) J. Jpn. Soc. Hortic. Sci. 60: 319-327.

Tabuchi, T. 2007. Chap. 2. Vegetables of solanaceae 1. General properties. (in Japanese) Vegetable crop science. (ed. by Kanahama, K.), Bun-eido Press, Tokyo, p 21-33.

Thomas, T. H. 1983. Effects of decapitation, defoliation and stem girdling on axillary bud development in Brussels sprouts. Sci. Hortic. 20: $45^{-51}$.

Tucker, D. J. 1975. Far-red light as a suppressor of side shoot growth in the tomato. Plant Sci. Lett. 5: 127-130.

Tucker, D. J. 1976. Endogenous growth regulators in relation to side shoot development in the tomato. New Physiol. 77: 561568 . 
Yanokuchi, Y. 1997. Basic edition. Tomato. V. Cultivation point and cultivation system. Cultivation of the processing tomatoes. Compendium of agricultural technology. Vegetables 2 (in Japanese) Tomato. Rural Cult. Assoc. Tokyo, p 607-613.

Yeager, A. F. 1927. Determinate growth in the tomato. J.
Hered. 18: 263-265.

Zhu, Y. X., Davis, P. J. 1997. The control of apical bud growth and senescence by auxin and gibberellin in genetic lines of pea. Plant Physiol. 113: 631-637. 